\title{
An Electrochemical Sensor based on conductive polymers/Graphite Paste Electrode for Simultaneous Determination of Dopamine, Uric acid and Tryptophan in Biological Samples
}

\author{
Farideh Hosseini Narouei ${ }^{1,2, *}$, Halimeh Kord Tammandani ${ }^{1}$, Younes Ghalandarzehi ${ }^{1}$, \\ Najmeh Sabbaghi ${ }^{1}$ And Meissam Noroozifar ${ }^{1 *}$ \\ ${ }^{1}$ Department of Chemistry, University of Sistan and Baluchestan, Zahedan, Iran \\ ${ }^{2}$ Department of Chemistry, University of Zabol, Zabol, Iran \\ *E-mail: Fnarui@gmail.com
}

doi: $10.20964 / 2017.08 .50$

Received: 11 April 2017 / Accepted: 6 June 2017 / Published: 12 July 2017

\begin{abstract}
A graphite paste electrode (GPE) modified with chemically synthesized Polythiophene nanostructures (PTh) was proposed for simultaneous voltammetric detection of Dopamine (DA), Uric acid (UA) and Tryptophan (Trp). The prepared electrode (PTh/GPE) showed a good improvment in catalytic activity of electrochemical oxidation DA, UA and Trp, leading to significant improves in the supposed peak currents and decreasing the peak potentials. In the calibration curve obtained from Linear sweep voltammetry it was illustrated the peak currents of DA, UA and Trp enhanced linearly with their concentration. The concentration range was found for DA, UA and Trp, 10-180 $\mu \mathrm{mol} \mathrm{L}^{-1}$, 6-180 $\mu \mathrm{molL}^{-1}$ and $6-180 \mu \mathrm{mol} \mathrm{L} \mathrm{L}^{-1}$ in $0.1 \mathrm{M}$ phosphate buffer solution ( $\mathrm{pH} 4.0$ ) respectively. The anodic peak height of analytes was investigated in different $\mathrm{pH}$ and scan rates and the optimum $\mathrm{pH}$ and scan rate was obtained. The LODs $(\mathrm{S} / \mathrm{N}=3)$ were $1,0.57$ and $0.61 \mu \mathrm{M}$ for $\mathrm{DA}$, UA and Trp, respectively. Consequently, the applicability of the voltammetric sensor was evaluated by simultaneous determination of DA, UA and Trp in biological samples. This present sensor showed valuable characteristics such as stability and repeatability during analytical experiments.
\end{abstract}

Keywords: Graphite paste electrode, Polythiophene nanostructures, Simultaneous determination, Electrochemical oxidation

\section{$\underline{\text { FULL TEXT }}$}

(C) 2017 The Authors. Published by ESG (www.electrochemsci.org). This article is an open access article distributed under the terms and conditions of the Creative Commons Attribution license (http://creativecommons.org/licenses/by/4.0/). 